\title{
Os sofredores de sintomas indefinidos: um desafio para a atenção médica
}

| ${ }^{1}$ Carla Ribeiro Guedes, ${ }^{2}$ Maria Inês Nogueira, ${ }^{3}$ Kenneth R. de Camargo Jr. |

Resumo: Os sofredores de sintomas indefinidos pacientes que apresentam sintomas sem uma lesão orgânica ou uma causalidade reconhecida - correspondem a uma parcela importante da demanda ambulatorial e podem ser considerados uma "anomalia" para o modelo biomédico, já que o mesmo negligencia a dimensão subjetiva do adoecimento. $\mathrm{O}$ atendimento qualificado desta demanda representa, ainda hoje, um desafio para a atenção médica. Neste artigo, apresentamos as principais estratégias utilizadas por médicos de diferentes especialidades, pertencentes ao hospital-escola de uma Faculdade de Medicina do Rio de Janeiro, para lidar com esta demanda. A partir de uma análise qualitativa de dez entrevistas com esses médicos, constatamos que a maioria deles apresenta estratégias limitadas e não resolutivas ao abordar esses pacientes. Uma das principais conclusões deste estudo é que tais dificuldades podem estar atreladas à formação médica, visto que as questôes ligadas à relação médico-paciente, sobretudo no que diz respeito aos aspectos subjetivos e à singularidade do sofrimento humano, não são valorizadas no ensino e tampouco na prática médica em geral.

> Palavras-chave: biomedicina, anomalia, sintomas indefinidos, subjetividade, prática médica.

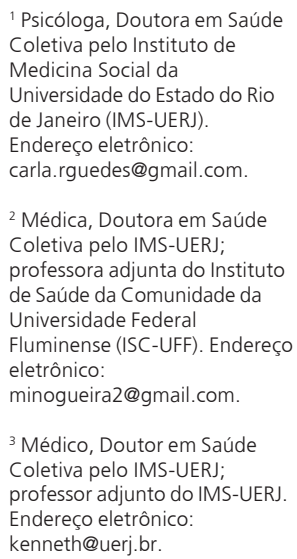




\section{Introdução}

A forma imprecisa como a biomedicina lida com os aspectos do adoecimento que escapam ao objetivismo da racionalidade científica moderna é uma questão que merece ser problematizada no âmbito da Saúde Coletiva, sobretudo porque concerne a sua prática cotidiana deparar com o sofrimento e com a singularidade humana. Portanto, parece-nos importante que todos esses elementos subjetivos presentes no adoecimento, nem sempre fáceis de se adequar à mensuração e à lógica causal exigida pelos cânones da ciência ao qual o modelo biomédico está submetido, sejam mais bem investigados.

A medicina ocidental contemporânea é hoje denominada, por muitos autores, de biomedicina, dada sua estreita vinculação com disciplinas oriundas das ciências biológicas. O referencial da clínica médica encontra-se na correlação entre doença e lesão. O médico tem como objetivo identificar a doença e sua causa, e entende que, ao remover a causa, ocorre a cura da doença. A díade doença-lesão aparece tão fortemente nas representaçôes do saber médico que se estabeleceu um conjunto de proposições implícitas norteadoras à prática do médico, denominado por Camargo Jr. (2003) de "teoria das doenças". Segundo esse autor, as doenças são vistas como coisas, com existência concreta, fixa e imutável, e se expressam através de um conjunto de sinais e sintomas que são manifestaçôes de lesões, e que, por sua vez, devem ser buscadas no âmago do organismo e corrigidas por algum tipo de intervenção concreta.

Essas proposições não aparecem explicitamente em livros ou manuais de ensino da medicina, mas são familiares a qualquer médico. A partir desta consideração, notamos que há pouco ou nenhum questionamento sobre essa condição por parte dos médicos; as doenças não são vistas como construções, ficções criadas e categorizadas por homens, mas efetivamente como entidades que existem autonomamente. Estas se apresentam, e cabe ao médico identificá-las, encontrar a lesão para, como diria Foucault (2001) em O nascimento da clínica, dar visibilidade àquilo que está invisível. A descoberta da lesão implicou a busca de uma causalidade, isto é, o desvendamento de uma cadeia lógica das influências causais que resultaram na patologia (HELMAN, 2003).

Paradoxalmente, ignora-se aquilo que deveria ser a categoria central que nortearia a prática médica: o médico, em última instância, deveria trabalhar sabendo que lida com um paciente que sofre e que esta experiência envolve uma série de questôes 
que escapam da dimensão biológica, pois se referem a questôes psicológicas, culturais e sociais. É frequente encontrarmos, na prática discursiva da medicina, referências à necessidade de uma abordagem biopsicossocial; mesmo assim, ainda existe uma total primazia do campo biológico sobre os demais. Desta forma, a biomedicina estaria direcionada para a descoberta de informações consideradas passíveis de quantificação e não voltada para outros aspectos, tais como sociais ou emocionais, que são dificilmente mensuráveis.

O método clínico tradicional, que consiste em o médico ouvir o paciente apresentar seus sintomas e sua evolução e, posteriormente, investigar seus sinais físicos, tem sido relegado em detrimento da tecnologia diagnóstica. Isso resulta num afastamento do método subjetivo de diagnóstico - que envolveria a subjetividade dos sintomas do paciente e a interpretação dos sinais físicos por parte do médico - e na ênfase em métodos objetivos. Desse modo, o levantamento e a mensuração dos fenômenos patológicos podem ser identificados através de recursos como tomografias, exames de sangue, radiografias, entre outros (HELMAN, 2003).

A partir disso, o médico procura a correspondência do sintoma com os fatores biológicos, a fim de que se possa diagnosticar a entidade patológica. Portanto, um sofrimento somente é tido como legítimo quando apresenta uma concretude em regularidades orgânicas classificáveis a partir de critérios anatômicos, fisiológicos, celulares e biomoleculares (BLANK, 1985). Desse modo, aquilo que possui legitimidade para o paciente não corresponde ao que é legítimo para o médico. $\mathrm{O}$ primeiro remete a suas sensações subjetivas, e o segundo transforma esse discurso em patologia inserida numa nosologia médica.

Os sintomas indefinidos, ao não se encaixarem nos referenciais taxonômicos da biomedicina, tornam-se um problema para o diagnóstico, colocando em xeque o saber médico, já que esses pacientes possuem persistentes sintomas físicos sem que o médico possa detectar uma doença. Entendemos que os portadores desse tipo de queixa não são pacientes, mas "quase-pacientes", visto que ficam vagando e estabelecendo uma rotina de ir e vir nas instituições de saúde sem que haja resolutividade de seus sintomas.

De acordo com a Organização Mundial de Saúde (OMS), a somatização constitui relevante questão de saúde pública mundial. Identificamos que esse tipo de manifestação corresponde a uma parcela importante da demanda ambulatorial; no entanto, ao receberem atendimentos inadequados, terminam por comprometer 
o potencial resolutivo da atenção médica e aumentam consideravelmente os custos dos serviços de saúde (GUEDES; NOGUEIRA; CAMARGO Jr., 2008).

Neste artigo, fruto da tese de doutorado $A$ subjetividade como anomalia: estratégias médicas para lidar com os sintomas vagos e difusos(GUEDES, 2007), procuramos mapear as estratégias dos médicos para lidar com sofredores de sintomas indefinidos. Trabalhamos com a hipótese subjacente de que esses sofredores, por não apresentarem uma lesão ou uma causalidade reconhecida, constituem-se numa anomalia - no sentido kuhniano - para o paradigma biomédico. Em linhas gerais, Kuhn (2003) afirma que as anomalias são problemas que não estavam previstos com os quais o cientista não se encontraria preparado para lidar. Assim como os cientistas, os médicos se deparam com enigmas e fracassos em seu cotidiano, e um deles seria o conjunto de sofrimentos considerados indefinidos.

Antecipando-nos à crítica da utilização de modelos epistemológicos na reflexão sobre a prática assistencial, gostaríamos de assinalar que embora as relações entre saber e prática no domínio da biomedicina sejam mais sutis e confusas do que o discurso de autoapresentação dos manuais médicos poderia levar a supor, a dimensão epistemológica segue se impondo no mínimo como norma técnica de legitimação e validação da ação médica. Adicionalmente, parece-nos plausível e heuristicamente útil empregar noções-chave que emergem do modelo kuhniano para estudar a interação saber-prática no domínio da atividade profissional do médico, por supormos que a mesma é ao menos análoga àquela dos cientistas no seu fazer:

Penso que supor, como Kuhn, a ciência como um empreendimento apenas parcialmente racional, e considerar o paradigma como determinante fundamental na forma como o cientista percebe o mundo, abre novas perspectivas no estudo de que chamei de paradoxos da clínica. Refiro-me em especial ao papel condicionante que as teorias correntes acerca das categorias diagnósticas e de sua gênese têm no modo como o médico traduz o sofrimento que seus pacientes apresentam, supervalorizando os aspectos objetiváveis, traduzidos em doença, e deixando de lado o universo subjetivo do sofrer. Proponho como hipótese de trabalho que essa dissociação se deve à existência de um paradigma clínicoepidemiológico, que condiciona a percepção do médico ao modelo da teoria das doenças. Sendo um paradigma, não é completamente enunciável em termos objetiváveis, e seu aprendizado tampouco se faz por proposições lógicas analiticamente decompostas, mas mediante exemplos (CAMARGO JR., 1992, p. 10-11 - grifos no original). 
Assim, ao fazermos uma analogia entre o significado da anomalia na ciência e sua utilização na prática assistencial em biomedicina, estamos lidando com um paradoxo. Se os fenômenos anômalos são considerados exceções no cotidiano de trabalho dos cientistas, constatamos que aquilo que entendemos como uma anomalia para o modelo biomédico - os sintomas indefinidos sem uma lesão correspondente - são manifestaçôes frequentes nos ambulatórios médicos. Dessa forma, o desafio da atenção médica é lidar com um tipo de manifestação que possui um caráter corriqueiro no cenário do cuidado em saúde.

\section{Abordagem metodológica}

No desenvolvimento da pesquisa que embasa este artigo, buscamos classificar e analisar as estratégias utilizadas pelos médicos formados e atuantes dentro da tradição biomédica para lidar com sofredores que apresentam sintomas indefinidos. Realizamos dez entrevistas semiestruturadas, no período de junho a setembro de 2006, sendo quatro com médicos especializados em clínica médica e seis com médicos pertencentes a diferentes especialidades: gastroenterologia (2), cardiologia (1), dermatologia (1), reumatologia (1) e medicina de família (1). Os entrevistados eram médicos pertencentes a um hospital-escola de uma das mais tradicionais e respeitadas Faculdades de Medicina do Rio de Janeiro.

A escolha dos entrevistados se deu através de indicações de "informantes privilegiados", isto é, profissionais de medicina que conheciam o hospital e os médicos que se destacavam em suas respectivas áreas. Inicialmente, tentávamos entrar em contato por telefone com cada médico a ser entrevistado, e apesar de nos identificarmos explicitando nossa instituição de origem, o nome do orientador do estudo e do profissional que o indicou, ouvimos muitas recusas com a mesma alegação: falta de tempo para tal atividade. Optamos, então, por reformular nossa estratégia diante dos outros entrevistados: passamos a abordá-los em seus ambientes de trabalho sem aviso prévio e pessoalmente realizávamos o convite. Essa tática mais diretiva teve efeito positivo - conseguimos agendar e realizar as entrevistas com os profissionais acima citados.

As entrevistas ocorreram em salas do próprio hospital-escola, todas foram gravadas com a permissão dos entrevistados, tendo sido transcritas posteriormente. Sua duração não foi preestabelecida, variando entre 30 minutos a uma hora e vinte aproximadamente, de acordo com o interesse dos entrevistados. De forma 
geral, os entrevistados mostraram-se bastante disponíveis durante as entrevistas, mesmo aqueles que tiveram resistência inicial. Muitos, inclusive, usaram um tempo maior do que haviam predeterminado.

Tanto o contato inicial quanto a abertura e o fechamento das entrevistas foram padronizados; os entrevistados foram informados de que se estava fazendo uma pesquisa para uma tese de doutorado sobre a assistência médica a pacientes com sintomas indefinidos, e em seguida eram convidados a assinar o termo de consentimento livre e esclarecido. As entrevistas eram iniciadas com duas perguntaspadrão: "qual a sua formação acadêmica?" e "como você definiria um bom médico?" Essas perguntas não tinham relevância em si mesmas, eram apenas dispositivos para que os entrevistados se sentissem mais à vontade. À medida que prosseguiam as entrevistas, eram realizadas perguntas que tangenciavam de forma indireta a questão a ser investigada: "quais os espaços institucionais em que mais gosta de atuar?" e "quais os tipos de pacientes de que mais gosta e que menos gosta de atender?" Somente as perguntas finais eram feitas mais claramente direcionadas aos pacientes com queixas vagas: "como se dá a seleção de informações ao fazer um diagnóstico de paciente com queixas indefinidas?" e "quais as estratégias e as condutas clínicas adotadas no tratamento destes pacientes?”

Essa abordagem - que no início era bastante indireta e progressivamente se tornou mais diretiva - foi escolhida de modo a minimizar a possibilidade de induzir os entrevistados a responder o que eles julgavam respostas "apropriadas", mesmo que estas não representassem adequadamente seus pontos de vista e suas condutas clínicas. Tal abordagem foi pensada também como uma estratégia para que o entrevistado fosse gradualmente se sentindo mais confortável com a entrevistadora.

A análise dos dados coletados foi feita a partir de uma leitura qualitativa. De acordo com os objetivos e as questóes do estudo, construímos um sistema classificatório que nos permitiu elaborar três categorias significantes: "Diagnóstico" (como os médicos realizam o diagnóstico de pacientes com sintomas indefinidos); "Tratamento" (como os médicos realizam o tratamento de sofredores com queixas indefinidas) e "Estratégias" (as estratégias médicas para lidar com pacientes com sintomas indefinidos).

Para análise do material empírico, recorremos a autores que problematizam a racionalidade biomédica (BONET, 2004; CAMARGO JR., 2003; CAMPOS, 2003 e 2006; FAVORETO, 2004; GUIMARÂES; LUZ, 2000; ONOCKO- 
CAMPOS, 2001 e 2006), a partir de uma abordagem epistemológica proposta por Kuhn (2003). A pesquisa foi devidamente aprovada pelo Comitê de Ética do Instituto de Medicina Social da Universidade do Estado do Rio de Janeiro.

\section{Resultados e análise}

\section{Perfil dos entrevistados}

O perfil dos entrevistados foi variado, levando-se em consideração as variáveis sexo, ano da graduação, titulação acadêmica e especialidade médica.

Houve predominância de homens (6) em relação às mulheres (4) no total dos indivíduos entrevistados. $\mathrm{O}$ tempo de graduação na época da realização da entrevista variou de 2 a 33 anos, com grande concentração de entrevistados graduados há mais de 20 anos (9).

Todos os médicos fizeram ou estavam fazendo algum tipo de pós-graduação: residência médica (4) e doutorado (6). Dentre as especialidades, a clínica médica foi predominante entre eles (4), seguida pela gastroenterologia (2), cardiologia (1), dermatologia (1), reumatologia (1) e medicina de família (1).

\section{Categorias}

\section{DIAGNÓSTICO}

a) Seleção de informações significativas

Foi mencionada uma pluralidade de táticas utilizadas pelos médicos para o estabelecimento do diagnóstico de um sofredor de queixas indefinidas. Alguns entrevistados citaram a importância de uma anamnese dirigida:

Costumo fazer uma anamnese dirigida, a gente procura seguir um roteiro de perguntas dirigidas para tentar definir melhor essas queixas... Eles [os pacientes] dizem "eu estou com uma dor no peito mas não sei bem onde é"... Então a gente pergunta se essa dor acontece durante o dia todo, se é mais manhã ou noite, se tem relação com o esforço, se vai para o braço... (médico 9).

Uma das entrevistadas reforça a importância da anamnese e afirma que, para certas queixas, é preciso estruturar um protocolo:

Acho que a anamnese é insubstituível, tanto que tem queixas que eu faço protocolo... Queda de cabelo é uma queixa que para a maioria dos dermatologistas é uma coisa 
meio desanimadora porque tem muitas causas... Com o protocolo você tem acesso aos dados familiares, história familiar, medicamentos que o paciente está usando... (médica 4).

Uma das médicas mencionou que costuma estabelecer uma priorização de queixas mais importantes:

Eu pergunto para o doente: "O que mais lhe incomoda?" Essa é a primeira pergunta que eu faço a ele... se ele não entende, eu explico: "O que é mais penoso para o senhor, o que mais atrapalha a sua vida?" Assim eu tento criar uma prioridade de sintomas que ele está apresentando. (médica 3).

Alguns entrevistados mencionaram a repetição da queixa pelo paciente ao longo das consultas como um critério importante para o estabelecimento do diagnóstico:

Às vezes os pacientes têm muitas queixas vagas e a partir do momento que você vai acompanhando o caso você vai vendo se ele repete a queixa.... No momento inicial o poliqueixoso te despeja um monte de queixas, mas com o decorrer do tempo você vai vendo que muitas delas foram um episódio único e que aquilo não era importante.... (médico 2)

O diagnóstico por exclusão também foi citado por alguns entrevistados como um procedimento relevante:

Embora seja dito que a conceituação de dispepsia funcional não seja um diagnóstico de exclusão... é um diagnóstico de exclusão... em certos casos você precisa fazer vários exames para afastar uma úlcera, câncer, etc... (médico 1).

Através das entrevistas, pudemos observar uma diversidade de estratégias para a seleção de queixas importantes referentes aos sintomas indefinidos, a maioria delas buscando sintomas mais consistentes e objetivos, que correspondam a um quadro taxonômico reconhecido em biomedicina.

De acordo com Bonet (2004), no momento de construção do diagnóstico médico, aparecem vários elementos como sentimentos, dúvidas, tentativas e erros, porém, no resultado final, isto desaparece, para que este diagnóstico adquira um estatuto de saber científico. Sendo assim, perdem-se as contextualizações históricas e sociais que se apresentavam no momento da sua construção e lhe é outorgado um critério de "objetividade". Apesar da tentativa dos médicos entrevistados de tornarem mais objetivo aquilo que é indefinido e impreciso, para que a biomedicina possa se adequar ao modelo preconizado pela ciência, o médico, em sua prática 
clínica, não consegue cumprir este ensejo, pois a subjetividade apresenta-se em vários momentos: na sua experiência, nas interpretaçōes dos exames, ao tomar decisões, julgamentos e na formulação diagnóstica (GUIMARÃES; LUZ, 2000).

b) Experiência profissional

A experiência do médico foi um dos temas mais comentados pelos entrevistados quando se referiram à habilidade/capacidade de estabelecer um diagnóstico adequado dos sofredores de queixas vagas e difusas. De acordo com alguns deles, o médico somente é hábil em selecionar no discurso do paciente as queixas relevantes para o diagnóstico quando tem experiência profissional:

Acho que com a experiência você acaba descobrindo com o passar do tempo o que deve valorizar ou não... dorzinha na ponta da unha não é para ser valorizada... agora uma falta de ar ou uma tonteira são coisas que você pode levar em conta... eu acho que isso é experiência do dia-a-dia. (médico 2).

Outro médico reafirma essa questão ao dizer que o médico experiente é capaz de realizar melhores julgamentos do discurso do paciente:

Para essa valorização.... essa análise crítica da queixa do indivíduo é preciso de estrada.... talvez esse seja um dos pontos que mais se requer o médico com experiência. Quando a gente fica mais velho a gente vai aprendendo a julgar melhor. (médico 8).

Por sua vez, uma das entrevistadas teme não ser capaz de selecionar adequadamente as queixas relevantes dos pacientes por inexperiência profissional:

Como eu me formei há pouco tempo, eu tenho medo de deixar passar alguma coisa importante daquele paciente que é poliqueixoso... de achar que aquela dor é mais uma dor dele e não uma dor que eu preciso valorizar. (médica 6).

A experiência profissional foi apontada pelos entrevistados como fator decisivo no diagnóstico de casos de pacientes com sintomas indefinidos. Os médicos acreditam que têm recursos mais eficazes para diagnosticar e tratar quando possuem uma longa trajetória no âmbito da clínica. Por sua vez, os médicos com pouco tempo de formação atribuíram à inexperiência seus temores em fazer um diagnóstico equivocado, como, por exemplo, afirmar que o paciente não tem nada, quando de fato possui alguma lesão não detectada. Esses achados coadunam-se com o que Camargo Jr. (2003) detectou em sua pesquisa sobre o 
conhecimento médico - de que há uma forte evidência da "primazia epistemológica da experiência” entre os médicos.

Assim, entende-se que a trajetória profissional pode ser um fator diferenciador na atenção ao sofredor de queixas indefinidas. Alguns médicos podem desenvolver uma "sabedoria prática", a qual se constituiria num modo singular de agir em situações clínicas que não seria expresso através das leis de generalidade e replicabilidade do modelo biomédico (FAVORETTO, 2004). Embora isso seja possível, as entrevistas nos mostram que esse não é o padrão habitual dos médicos, pois esse "novo agir" não foi devidamente trabalhado em suas formações. Portanto, lidar com os aspectos subjetivos presentes no adoecimento continua a ser um grande desafio para os praticantes da biomedicina, ainda que possuam vasta experiência profissional.

\section{TRATAMENTO}

a) Dificuldades no tratamento

Uma parcela significativa dos médicos entrevistados relatou dificuldades no tratamento de pacientes que apresentam sintomas indefinidos. Um dos entrevistados remeteu essas dificuldades à inexistência de uma correlação causal bem definida dos sintomas encontrados:

São sintomas vagos, engasgo, sensação de plenitude, empanzinamento, todas aquelas coisas que teoricamente são muito difíceis de tratar... O indivíduo geralmente tem sintomas que você não chega a lugar nenhum... você conversa, conversa, passa um remédio que sabe que não vai funcionar... você procura justificativas para os sintomas e não acha nada. (médico 1).

Uma das entrevistadas revela o despreparo para lidar com queixas que envolvam conteúdos emocionais:

Às vezes o paciente começa a conversar, fala sobre queixas completamente vagas e passam uns quinze minutos e você não sabe o motivo da consulta... eu acho muito desestimulante... porque às vezes é um problema que não está ali, a dermato tem um lado emocional muito grande e é uma área que a gente não tem muito domínio... (médica 4).

Um dos médicos abordou o baixo nível social e cultural dos pacientes como um dos empecilhos ao tratamento: 
Aqui, por exemplo, em geral o indivíduo não tem bom nível cultural... a parte financeira dele é muito baixa... as questões de vida dele são extremamente sérias... ele somatiza... e aí fica difícil para você explicar isso... (médico 1).

Observamos que alguns entrevistados demonstraram desconforto ao se deparar com os fatores emocionais que se apresentam entrelaçados aos sintomas físicos dos pacientes. A queixa subjetiva incomoda, irrita e é vista como uma interferência na condução do quadro clínico. Por sua vez, a médica que abordou o baixo nível social e cultural dos pacientes remete-nos a Boltanski (1989). Segundo ele, a relação doente-médico é sempre uma relação de classe, na qual a atitude do médico se modifica de acordo com a classe social do paciente. Para o médico, o doente pertencente à classe popular é hierarquicamente inferior e se encontra incapaz de compreender sua linguagem.

Além do problema ligado à classe social do paciente, identificamos que a dificuldade dos médicos em lidar com a anomalia - sintomas indefinidos sem lesão aparente - é inerente ao próprio modelo biomédico, ou seja, é um obstáculo epistemológico desse modelo. De acordo com Kuhn (2003, p. 95), a anomalia produz fracassos na resolução dos enigmas cotidianos e gera insegurança profissional: "essa insegurança é gerada pelo fracasso constante dos quebra-cabeças da ciência normal em produzir os resultados esperados".

De forma similar, os pacientes, ao apresentarem sintomas que não se encaixam com facilidade na "categoria doença" proposta pelo modelo biomédico, acabam por dificultar o diagnóstico e gerar insucessos clínicos. Acreditamos, portanto, que a irritação dos médicos em relação aos sofredores de queixas indefinidas é uma reação ao fracasso terapêutico e à insegurança produzida por esse tipo de demanda.

\section{Vínculo médico-paciente}

Uma parcela significativa dos entrevistados afirmou que o vínculo entre o médico e o paciente é um dos principais fatores a ser levado em consideração no tratamento de sofredores com sintomas indefinidos:

A condução deste tipo de problema vai muito do rapport entre o médico e o doente... se ele tem confiança em você e se você tiver paciência, ele já começa a melhorar... só com a conversa com o médico o doente já melhora $40 \%$ daquilo que ele está sentindo. (médico 1). 
Um dos entrevistados afirmou que, estabelecendo uma boa relação com o doente, é mais fácil convencê-lo de que seu estado de saúde está normal:

Geralmente com uma boa relação médico-paciente a gente tenta mostrar que está tudo normal... O exame físico já foi feito na primeira consulta... agora refez e confirma: "Olha, está vendo? Está bem a pressão, o coração, o abdômen está direitinho...” Às vezes isso já basta... Você sendo firme e atencioso com o doente ele fica satisfeito. (médico 10).

Grande parte dos entrevistados ressaltou a importância da relação médicopaciente no tratamento de sofredores com queixas indefinidas. Contudo, a construção de uma "relação", de um "vínculo", torna-se extremamente difícil quando não se consideram os aspectos subjetivos que se apresentam nesse encontro.

Em estudo etnográfico (GUEDES, 2007), observamos que os médicos não concebem a relação médico-doente como uma relação de fato, na qual uma dimensão intersubjetiva está em jogo, com fatores conscientes e inconscientes atuando nessa dinâmica, incluindo, como ressalta Campos (2006), a transferência e a contratransferência. Dessa forma, os médicos não conseguem se distanciar e perceber o processo com todas as nuanças que este exige e, portanto, não podem agir no problema, mas apenas reagir a ele.

\section{ESTRATÉGIAS}

a) O paciente "não tem nada"

Alguns entrevistados utilizavam a simples estratégia de dizer claramente ao paciente que ele "não tem nada", pois isso evitaria que o mesmo continuasse supervalorizando queixas sem importância:

Uma estratégia é você dizer: "Não, não é nada”... isso vai funcionar de acordo com a sua sensibilidade de perceber que dizer isso seria melhor naquele momento para aquele paciente... porque às vezes parece que você está dando uma corda enorme para as coisas que ele está te trazendo e a coisa não tem fim.... (médica 3).

Um dos médicos afirmou que o paciente "não tem nada" quando seus sintomas estão relacionados com fatores emocionais:

Essa dor que o senhor tem quando fica nervoso e tenso... isto não tem valor nenhum... A gente já investigou, já viu que isso não é importante. (médico 2). 
De acordo com Kuhn (2003), as primeiras reações dos cientistas quando tomam consciência da anomalia é negá-la ou afastá-la da vista. Em analogia com a assistência médica, podemos observar que, diante dos poucos recursos oferecidos pelo paradigma biomédico para que praticante possa se defrontar com as manifestações subjetivas do adoecimento, uma das formas, aliás muito frequente, de lidar com os sintomas indefinidos é através da negação. Assim, esses "quase-pacientes" transformam-se num problema e terminam por serem relegados à margem da instituição médica.

a) Encaminhamentos "psis"

Quando suspeitam que os sintomas físicos apresentam relações com fatores psicossociais, uma grande parcela dos médicos afirmou que a melhor estratégia a ser utilizada nesses casos é o encaminhamento a profissionais da psicologia e da psiquiatria:

Tem casos que você não vê muita razão da consulta... porque às vezes o problema não está ali ... o problema é estresse, problemas financeiros e familiares... e aí é uma área que a gente não tem muito... quer dizer, eu acho que tem outros profissionais como a psicologia e a psiquiatria que podem ajudar melhor... Então você acaba tendo que encaminhar mesmo... (médica 4).

Um dos entrevistados mencionou que é uma obrigação do médico dizer ao paciente que ele necessita de um tratamento psicoterápico:

O médico pode até não resolver a encrenca psicológica do paciente... mas ele é obrigado a identificar e oferecer a proposta: "Olha... a senhora precisa de uma psicoterapia... a senhora precisa encontrar um caminho para resolver essas questóes”. (médico 8).

Como mencionamos anteriormente, na biomedicina há um grande anseio por uma prática clínica científica. Por conseguinte, a objetivação do paciente tornouse uma necessidade. Esse olhar clínico se estruturou no século XIX, com o advento da anatomia patológica. Entretanto, Freud, no início do século XX, propôs uma clínica diferenciada, baseada não somente no olhar, mas na escuta. De acordo com Onocko-Campos (2001), a proposta freudiana coloca no centro da relação clínica a escuta e a fala do paciente, e não mais a visão objetiva do profissional. Contudo, como podemos constatar nessas entrevistas, os médicos continuam a cindir essas 
duas dimensões e chegam a criar settings distintos para trabalhar com elas. De um lado, as consultas médicas - puro olhar e externalidade - e de outro lado, consultas psicológicas - pura escuta (CAMPOS, 2006).

A partir desses resultados, consideramos que a proposta de uma clínica ampliada, sugerida por Campos (2003), ainda é um desafio para a atenção médica, uma vez que esta depende de (re)colocar essas duas dimensões integradas.

\section{b) Medicação}

Vários entrevistados relataram que recorrem ao uso de medicamentos "sintomáticos" - remédios que visam à eliminação dos sintomas físicos apresentados pelo sofredor de queixas vagas. Vejamos uma fala que exemplifica esse procedimento:

Em geral eu receito sintomáticos... na maioria das vezes, na minha especialidade, os indivíduos somatizam muito... é muito comum terem flatulência... então é só você passar um remédio que não tem efeito colateral nenhum e ele realmente melhora com isso... (médico 1).

O uso de medicação antidepressiva também foi apontado como uma estratégia eficaz, sobretudo nos casos de sofredores de queixas indefinidas cujos sintomas físicos expressam um quadro de depressão:

Eu tive uma doente que teve herpes zoster que deixa uma dor horrível depois... e a doente tinha uma nevralgia pós-herpética há muitos anos... Alguém a encaminhou para mim e então eu conversei com ela, examinei e disse: "Olha, a senhora já tomou todos os medicamentos que eu conheço para nevralgia pós-herpética, não tenho nada de novo para oferecer que eu conheça. A senhora fez todos os exames corretos". E a partir disso começou uma conversa que eu descobri o real motivo da dor dela... ela tinha problemas familiares enormes, estava arrasada e cheguei a um diagnóstico de quadro de depressão importantíssimo...Tratei a depressão dela com antidepressivo e ela ficou ótima. (médico 10).

A partir dessas falas, parece-nos que a prescrição de medicamentos ainda é a principal ação terapêutica empregada pelos médicos nos casos de pacientes com sintomas indefinidos, na medida em que há poucos recursos para lidar com a anomalia - a dimensão subjetiva do adoecimento.

$\mathrm{Na}$ maioria dos casos, os sofredores de queixas indefinidas são tratados a partir dos referenciais biologizantes e de objetividade, e suas questões subjetivas 
são submetidas à medicação em série: “... tudo que se refere à subjetividade, ao imaginário (por exemplo), é posto de lado como não científico, sendo objeto de uma 'farmacologização' tão maciça quanto cega - sempre em nome da ciência" (CAMARGO Jr., 2003, p. 77).

\section{Considerações finais}

Através deste estudo pudemos constatar que, apesar de todos os esforços da biomedicina em negar a dimensão subjetiva, esta se apresenta de forma evidente nos sofredores de sintomas indefinidos. O modelo biomédico, pautado pela objetividade do discurso científico, é colocado em xeque na medida em que o médico se depara com sintomas físicos sem que seja encontrada em suas bases conceituais uma justificativa para tais fenômenos. Compreendemos que essas dificuldades podem estar atreladas à formação médica, visto que as questões ligadas à relação médico-paciente, sobretudo no que diz respeito aos aspectos subjetivos e à singularidade do sofrimento humano, não são valorizadas no ensino e tampouco na prática médica em geral.

As novas diretrizes curriculares do ensino médico, homologadas em 2001, estão estimulando as escolas médicas a incluirem no ensino uma abordagem dos aspectos psicológicos e sociais do processo saúde-doença. Embora essas iniciativas ainda não sejam hegemônicas, há relatos de experiências inovadoras em faculdades médicas de todo o país (KOIFFMAN, 2001; REGO, 2003; PINHEIRO et al., 2005; SILVEIRA; LEAL, 2006), com novas proposiçōes para se pensar o adoecimento, tais como: a valorização das tecnologias relacionais, a clínica ampliada, a humanização do atendimento, as discussões sobre a integralidade das ações de saúde e a produção do cuidado com vistas à transformação do modelo tecno-assistencial.

De acordo com Mehry (2004), as tecnologias em saúde abarcam diferentes dimensões tanto material quanto de ordem não-material. Essas dimensões são divididas em três categorias: dura, leve-dura e leve. A tecnologia dura seria representada pelos equipamentos e máquinas; a leve-dura corresponderia aos saberes clínico e epidemiológico; e a leve seria dada pelos modos relacionais de agir no ato de cuidar. Assim, um modelo de saúde deveria estar centrado nas tecnologias leves e leve-duras, ao contrário do que se vê no modelo atual, com ênfase nas tecnologias duras e leve-duras. Concordamos com o autor, quando diz que é necessário que se produzam novos sentidos para os atos de cuidar, e que estes correspondam às 
necessidade dos usuários, uma vez que a finalidade de qualquer trabalho em saúde é operar com saberes tecnológicos que levem à produção do cuidado.

Entretanto, podemos constatar, através de teses recentes, que as tecnologias relacionais não são incluídas na formação médica tradicional. Observamos o ambulatório de gastroenterologia de um hospital universitário, em pesquisa etnográfica, e verificamos que o preceptor desse serviço, apesar de investir na relação médico-paciente e valorizar questões subjetivas trazidas pelos pacientes, não viabilizava a transmissão dessa abordagem no ensino e treinamento dos residentes sob sua supervisão (GUEDES, 2007).

Por sua vez, Favoreto (2007), ao estudar a narrativa como técnica de investigação da clínica na medicina, entrevista e observa a supervisão de médicos de família de um dos programas mais tradicionais e bem-sucedidos do país. A partir daí, constatou a capacidade dos médicos do programa de elaborar uma narrativa includente, que contemplava aspectos para além do estritamente biológico. Ainda assim, verificou que esse saber permanece "subordinado ao modelo biológico-cientificista, que é o tipo de narrativa que predomina, por exemplo, na exposição de casos na supervisão" (CAMARGO JR, 2007, p. 110).

De um modo geral, as questóes ligadas às tecnologias relacionais, ao ato terapêutico em si, que dizem respeito à subjetividade do paciente, não são vistas como pauta de ensino, como importantes para a formação do médico. Estas habilidades são consideradas características pessoais dos médicos e são desenvolvidas de acordo com a sensibilidade de cada profissional.

Visando à transformação dessa situação, alguns autores da área de Saúde Coletiva defendem que a introdução de formação específica no campo relacional poderia instrumentalizar os profissionais de saúde para uma melhor atuação. Para tal, é preciso recuperar conteúdos e estratégias educacionais que permitam contemplar o conhecimento de tecnologias leves e, ao mesmo tempo, oferecer oportunidade de vivência constante dessas abordagens em suas realidades institucionais (SILVA JR.; MERHY; CARVALHO, 2003).

Encerramos este estudo esperando que o debate em torno da assistência médica aos sofredores de sintomas indefinidos não se esgote nestas páginas e que nosso trabalho possa contribuir de alguma forma para que a própria biomedicina reflita sobre seus caminhos e descaminhos. Não nos propomos a dar respostas fechadas ou a oferecer modelos a serem seguidos; acreditamos, contudo, que o investimento 
numa formação médica renovada, que de fato inclua as tecnologias relacionais como instrumental a ser utilizado na prática clínica, possa contribuir para uma abordagem mais resolutiva das manifestações subjetivas do adoecer.

\section{Referências}

BLANK, N. Raciocínio clínico e os equipamentos médicos: subsídios para a compreensão do significado do equipamento diagnóstico: terapêutica para a medicina. Dissertação (Mestrado emSaúde Coletiva) - Instituto de Medicina Social, Universidade do Estado do Rio de Janeiro, Rio de Janeiro, 1985.

BONET, O. Saber e sentir: uma etnografia da aprendizagem da biomedicina. Rio de Janeiro: Fiocruz, 2004. p. 136.

BOLTANSKI, L. As classes sociais e o corpo. Rio de Janeiro: Graal, 1989.

CAMARGO JR., K. R Paradigmas, ciência e saber médicos. Rio de Janeiro: IMS-UERJ, 1992 (Série Estudos em Saúde Coletiva, 6).

. Biomedicina, saber é ciência: uma abordagem crítica. São Paulo: Hucitec, 2003.

. A filosofia empírica da atenção à saúde. In: PINHEIRO, R.; MATTOS, R. A (Org.). Razões

públicas para a integralidade em saúde: o cuidado como valor. Rio de Janeiro: Cepesc, 2007. p. 101-126.

CAMPOS, G. W. S. Por uma clínica do sujeito. In: . Saúde Paideia. São Paulo: Hucitec, 2003. p. 140-162.

Reforma da Reforma. São Paulo: Hucitec, 2006. p. 223.

FAVORETO, C. A. O. A velha e a renovada clínica dirigida à produção de um cuidado integral em saúde. In: PINHEIRO, R.; MATTOS, R. A. (Org.). Cuidado: as fronteiras da integralidade. Rio de Janeiro: Cepesc, 2004. p. 205-19.

. A narrativa da e sobre a clínica na atençāo primária: uma reflexão sobre o modo de pensar e sobre o modo de agir dirigido ao diálogo, à integralidade e ao cuidado em saúde. Tese (Doutorado em Saúde Coletiva) - Instituto de Medicina Social, Universidade do Estado do Rio de Janeiro, Rio de Janeiro, 2007.

GUEDES, C. R. A subjetividade como anomalia: estratégias médicas para lidar com os sintomas vagos e difusos em biomedicina. Tese (Doutorado em Saúde Coletiva) - Instituto de Medicina Social, Universidade do Estado do Rio de Janeiro, Rio de Janeiro, 2007.

GUEDES, C. R.; NOGUEIRA, M. I.; CAMARGO JR., K. R. A subjetividade como anomalia: contribuiçōes epistemológicas para a crítica do modelo biomédico. Revista Ciência e Saúde Coletiva. Rio de Janeiro, v. 11, n. 4, p. 1.093-1.103, 2006.

. Os sintomas vagos e difusos em biomedicina: uma revisão da literatura. Revista Ciência e Saúde Coletiva. Rio de Janeiro, v. 13, n. 1, p. 135-144, 2008. 
GUIMARÃES, M. B.; LUZ, M. T. Intuição e arte de curar: pensamento e ação na clínica médica. Rio de Janeiro: iMS-UERJ, 2000 (Série Estudos em Saúde Coletiva, 203).

HELMAN, C. G. Cultura, saúde e doença. Porto Alegre: Artmed, 2003.

KOIFMAN, L. O modelo biomédico e a reformulação do currículo médico da Universidade Federal Fluminense. História, Ciências, Saúde-Manguinhos, v. 8, n. 1, p. 48-70, 2001.

KUHN, T. A estrutura das revoluçôes científicas. São Paulo: Perspectiva, 2003.

MERHY, E. E. Um dos grandes desafios para os gestores do SUS: apostar em novos modos de fabricar os modelos de atenção. In: MERHY, E. E. et al. (Org.). O trabalho em saúde: olhando e experienciando o SUS no cotidiano. São Paulo: Hucitec, 2004. p. 67-92.

ONOCKO-CAMPOS, R. T.; CAMPOS, G. W. S. Co-construção de autonomia: o sujeito em questão. In: CAMPOS G. W. S. et al. (Org.). Tratado de Saúde Coletiva. São Paulo: Hucitec, 2006. p. 669-688.

ONOCKO-CAMPOS, R. T. Clínica: a palavra negada, sobre as práticas clínicas nos serviços substitutivos de saúde mental. Saúde em Debate, Rio de Janeiro, n. 25, v. 58, p. 98-111, 2001.

PINHEIRO, R.; CECCIM, R. B.; MATTOS, R. A (Org.). Ensinar saúde: a integralidade e o SUS nos cursos de graduação na área da saúde. Rio de Janeiro: Cepesc, 2005.

REGO, S. A formação ética dos médicos: saindo da adolescência com a vida (dos outros) na mão. Rio de Janeiro: Fiocruz, 2003.

SILVA JR., A. G.; MERHY, E. : CARVALHO, L. C. Refletindo sobre o ato de cuidar da Saúde. In: PINHEIRO, R.; MATTOS, R. A. (Org.). Construção da integralidade: cotidiano, saberes e práticas em saúde. Rio de Janeiro: Cepesc, 2003. p. 113-128.

SILVEIRA, R.; LEAL, O. A importância da clínica na atenção primária: a estratégia de formação da Universidade Federal do Acre. In: PINHEIRO, R.; MATTOS, R. A. (Org.). Gestão em redes: práticas de avaliação, formação e participação na saúde. Rio de Janeiro: Cepesc, 2006. p. 321-332. 


\section{Abstract}

Sufferers of undefined symptoms: a challenge for medical attention?

Sufferers of undefined symptoms - patients who have symptoms without an organic lesion or a recognized link - represent a significant portion of the outpatient clinic and can be considered an "anomaly" to the biomedical model, since it neglects the subjective dimension of illness. The qualified service for this demand is even today a challenge for medical attention. This paper presents the main strategies used by physicians of different specialties, belonging to the hospital in a medical school in Rio de Janeiro, to cope with this demand. From a qualitative analysis of ten interviews with these doctors, we found that most of them have limited and not resolving strategies to approach these patients. One of the main conclusions of this study is that such difficulties can be tied to medical education, as the issues of doctor-patient relationship, particularly with regard to subjective aspects and the uniqueness of human suffering, are not valued in education nor in medical practice in general.

> Key words: anomaly; biomedicine; undefined symptoms; subjectivity; medical practice. 